
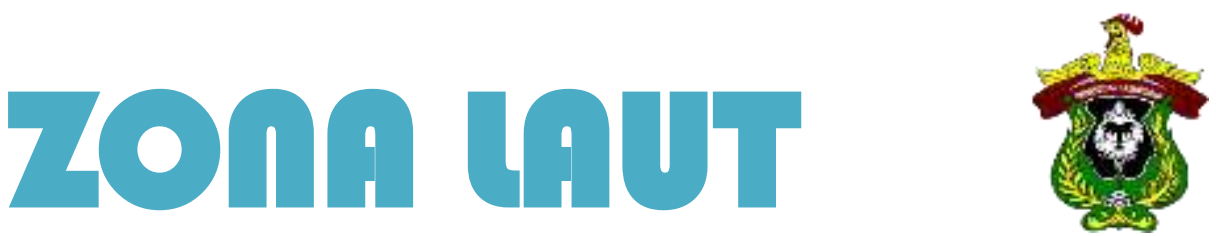

\title{
PROSES PENGUJIAN KEBOCORAN VALVE PADA KM. KENDHAGA NUSANTARA MENGGUNAKAN HYDROSTATIC PRESSURE TEST
}

\author{
*Adi Kurniawan Yusim, Muhammad Afif Fadila dan Sarwoko \\ Prodi Teknologi Rekayasa Konstruksi Perkapalan Sekolah Vokasi Undip \\ * adiyusim.vokasi@live.undip.ac.id
}

\begin{abstract}
Abstrak
Proses uji kebocoran pada valve (katup) pada kapal merupakan tahapan yang penting dilakukan dan telah diatur oleh Biro Klasifikasi Indonesia (BKI) sebagai Klas yang mengacu pada The International Association of Classification Societies (IACS). Pipa dan alat fitting harus diuji pada tekanan hidrostatik tidak kurang dari 1,5 kali tekanan nominal. Pada penelitian ini, 4 buah gate valve yang diuji memiliki tekanan nominal dari pabrikan sebesar 10 bar, sehingga harus diuji hingga tekanan 15 bar. Katup telah diuji satu per satu dengan metode Hydrostatic Pressure Test yaitu menggunakan Test Pump. Dari hasil pengujian ditemukan kebocoran pada salah satu valve yaitu pada bagian disc. Rekomendasi yang diberikan oleh pihak BKI untuk kebocoran tersebut adalah diperbaiki dengan cara menutupi kebocoran menggunakan bahan yang disarankan dari pabrikan pembuatan gate valve tersebut yaitu menggunakan lem besi tipe epoxy.
\end{abstract}

Kata Kunci: Uji Kebocoran, Gate Valve, Hydrostatic Pressure Test.

\begin{abstract}
The process of testing the leak on the valve on the important stages of vessels is carried out and regulated by the Biro Klasifikasi Indonesian (BKI) as a Class which refers to the International Association of Classification Societies (IACS). Pipes and fittings shall be tested by hydrostatic pressure not less than 1.5 times the nominal pressure. In this study, the 4 gate valves tested had a nominal pressure from the manufacturer of $10 \mathrm{bar}$, so they had to be tested up to a pressure of 15 bar. The valves have been tested one by one with the Hydrostatic Pressure Test method, using the Test Pump. From the test results found a leak in one of the valves, namely in the disc. The recommendation given by BKI is to repair it by covering the leak using the material recommended from the gate valve manufacturer (using epoxy type iron glue).
\end{abstract}

Keyword: Repair, Gate Valve, Hydrostatic Pressure Test.

\section{PENDAHULAN}

Penyebab kecelakaan kapal yang biasa terjadi adalah tabrakan, kegagalan peralatan, ledakan, kebakaran, kebocoran, kandas, terbalik, dan tenggelam [1]. Data laporan investigasi KNKT tahun 2010 - 2016 terjadi 54 kasus kecelakaan kapal dengan berbagai tipe kapal.

Pembangunan KM. Kendhaga Nusantara merupakan kerja sama antara PT. Krakatau Shipyard dengan PT. Dok \& Perkapalan Kodja Bahari (Persero). Kapal ini merupakan kapal perintis untuk menunjang poros maritim dan dipesan oleh Direkorat Jenderal Perhubungan Laut, Kementerian Perhubungan Republik Indonesia [2]. Pihak-pihak yang terkait dalam pengujian kebocoran valve antara lain owner dan owner surveyor, surveyor dari Klas (Biro Klasifikasi Indonesia), dan divisi Quality Control (Galangan).

Valve adalah komponen penting dalam aliran fluida atau sistem tekanan yang mengatur aliran atau tekanan fluida. Fungsi dari valve yaitu membuka dan menutup aliran, mengendalikan laju aliran, mengalihkan aliran, mencegah aliran balik, mengendalikan tekanan, atau mengurangi tekanan. Fungsi-fungsi tersebut dilakukan dengan menyesuaikan posisi penutup dari valve. Ini dapat dilakukan secara manual atau otomatis [3]. Gate 
valve adalah jenis stop valve. Valve ini tidak untuk mengatur besar kecil laju suatu aliran fluida dengan cara membuka setengah atau seperempat posisinya. Jadi, posisi gate pada valve ini harus membuka penuh (fully open) atau menutup penuh (fully close). Parallel gate valves adalah katup geser dengan bagian penutup parallel-face-gate. Bagian penutup ini dapat terdiri dari cakram/disk tunggal atau disk kembar dengan mekanisme penyebaran di antaranya. Gaya yang menekan disk pada dudukan dikendalikan oleh tekanan fluida yang bekerja pada disk apung. Salah satu keunggulan parallel gate valves adalah resistansinya yang rendah terhadap aliran, yang dalam kasus katup bore penuh mendekati panjang pipa lurus. Karena disk meluncur melintasi permukaan dudukan, parallel gate valves juga mampu menangani cairan, yang membawa padatan dalam suspensi.

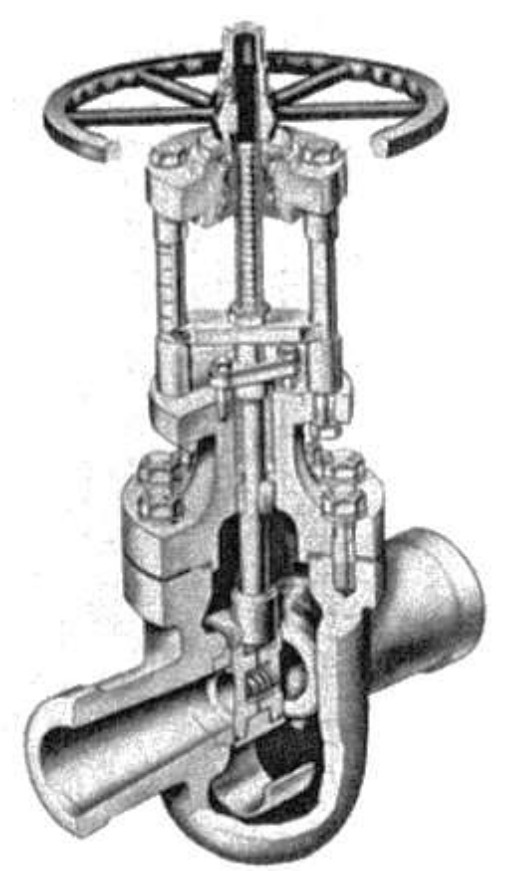

Gambar 1. Parallel slide gate valve dengan bagian aliran konvergen-divergen [3]

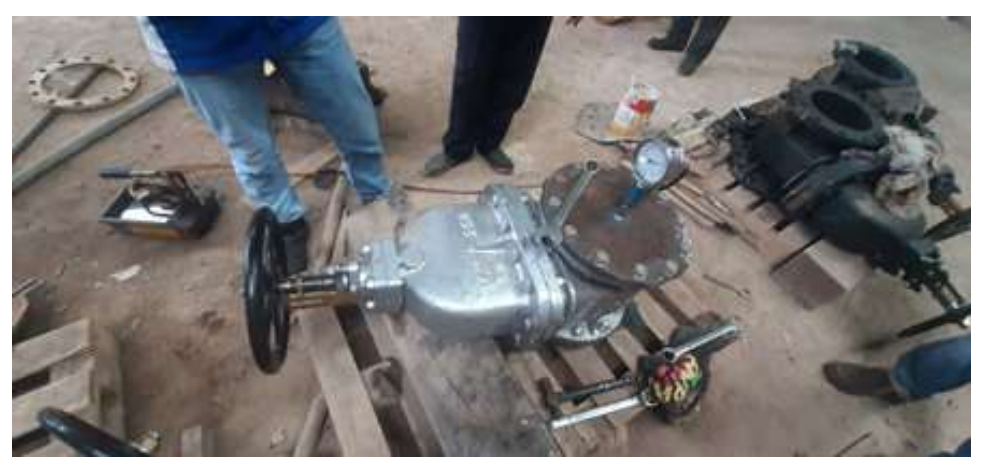

Gambar 2. Pengisian air pada valve yang diuji

\section{METODE}

Proses uji kebocoran gate valve menggunakan metode hydrostatic pressure test yaitu metode pengujian kekedapan pengelasan dan sambungan dengan bantuan air bertekanan. Hydrostatic Pressure Test umumnya digunakan untuk pengujian kekedapan pengelasan pada instalasi pipa-pipa di dalam kapal. Metode yang digunakan dalam penelitian ini adalah pengamatan di galangan kapal PT. Krakatau Shipyard, Bojonegara. Kapal yang diamati adalah kapal negara tipe kontainer 100 TEUS (bangunan baru) KM. Kendhaga Nusantara. Tujuan dari pengamatan ini adalah untuk mengetahui kebocoran dari 4 gate valve yang dipakai pada kapal ini. Kebocoran ini menimbulkan turunnya kinerja dari valve itu sendiri sehingga tidak dapat bekerja secara baik dan maksimal. 


\subsection{Spesifikasi Gate Valve}

Gate valve adalah katup yang paling banyak dipasang di kapal. Fungsinya adalah untuk membuka dan menutup aliran fluida cair (air, minyak, bahan bakar, minyak lumas) dan udara. Aplikasi katup ini pada kapal antara lain instalasi pipa bahan bakar, minyak lumas, air tawar, bilga atau ballast, pendingin mesin, pemadam, general service dan sea chest. Jenis gate valve pada penelitian ini adalah katup gerbang bonnet tekanan rendah.

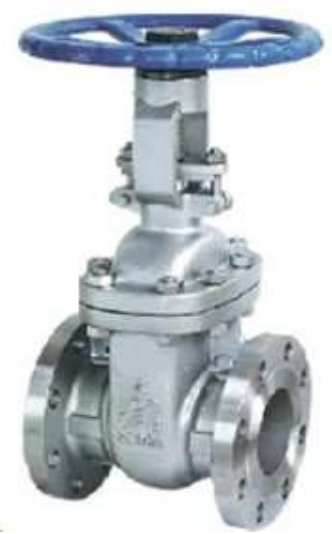

Gambar 3. Gate valve tekanan rendah

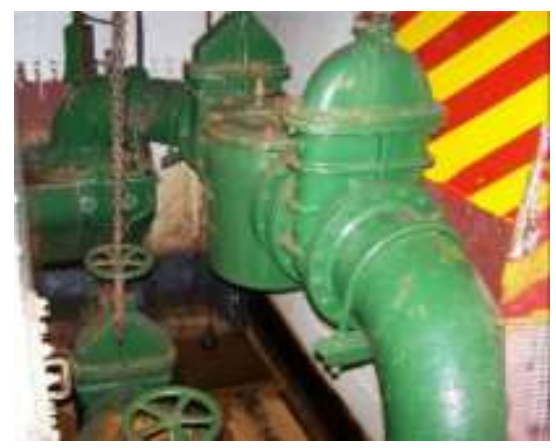

Gambar 4. Gate Valve yang dipasang pada Sea Chest [4]

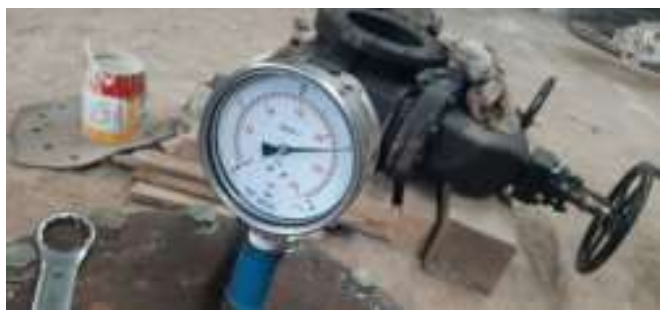

Gambar 5. Pressure Gauge

2.2. Proses Pengujian Gate Valve

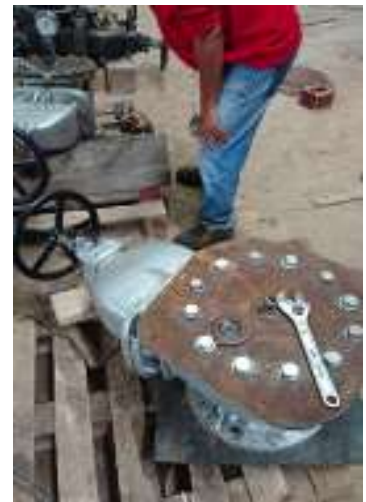

Gambar 6. Gate Valve yang diuji

copyright is published under Lisensi Creative Commons Atribusi 4.0 Internasional. 
Gate valve terbuat dari bahan forged steel yang khusus dirancang untuk mampu pada tekanan tinggi. Gate valve sering mengalami kegagalan yang diakibatkan oleh korosi. Bagian-bagian dari gate valve dapat dilihat pada Gambar 7.

Dalam proses pengujian gate valve perlu dilaksanakan sesuai dengan Rules BKI volume III tahun 2016 tentang Machinery Installation. Adapun tahap-tahap yang dilakukan dalam proses pengujian gate valve yang sudah dilaksanakan di PT. Krakatau Shipyard adalah sebagai berikut:

\subsubsection{Pra Pengujian}

Sebelum pengujian, biasanya dilakukan rapat untuk membahas hal yang akan dikerjakan. Pada rapat itu dihadiri pihak galangan, surveyor klas, owner dan owner surveyor. Beberapa hal teknis yang harus dipersiapkan sebagai berikut:

a. Penentuan instalasi yang akan diuji, untuk pengujian ini dilakukan pengujian pada 4 buah gate valve.

b. Pemastian semua bagian pada gate valve lengkap dan utuh.

c. Persiapan alat uji yang akan digunakan, untuk pengujian Hydrostatic Pressure Test yaitu menggunakan Test Pump.

d. Pemasangan packing dan baut dengan rapat serta pakem.

e. Pembukaan handwheel dan sambungkan dengan Test Pump.

\subsubsection{Proses Pengujian}

Tahap ini dilaksanakan setelah proses persiapan (pra pengujian), dengan cara:

a. Pengisian air kedalam gate valve yang sudah terpasang semua bagiannya.

b. Penyambungan peralatan yaitu Test Pump dan Pressure Gauge.

c. Pengisian air pada bak alat Test Pump.

d. Pemompaan air ke dalam gate valve yang diuji agar memiliki tekanan yang cukup dengan cara menggerakan tuas yang ada pada alat Test Pump agar air di dalam bak alat (Test Pump) terpompakan ke dalam benda uji.

e. Perhatian pada Pressure Gauge, apabila tekanan yang diinginkan sudah tecapai maka hentikan pemompaan.

f. Pemeriksaan dengan seksama bagian-bagian gate valve yang diuji, jika mengalami kebocoran maka ada air yang tersembur keluar.

\section{HASIL DAN PEMBAHASAN}

Proses pengujian harus dilakukan sebelum gate valve dipasang di atas kapal. Pada pengujian ini, pihak Klas (BKI) memiliki hak untuk memeriksa dan memberikan rekomendasi kepada pihak Owner. Ada beberapa bagian penting yang diperiksa oleh Klas pada valve. Berdasarkan hasil pengujian gate valve di galangan menunjukkan bahwa kegagalan material yaitu terdapat kebocoran pada bagian disc, dapat dilihat pada Gambar 6. Gate valve yang diuji memiliki tekanan nominal dari pabrikan sebesar 10 bar, sehingga harus diuji hingga tekanan 15 bar [5].
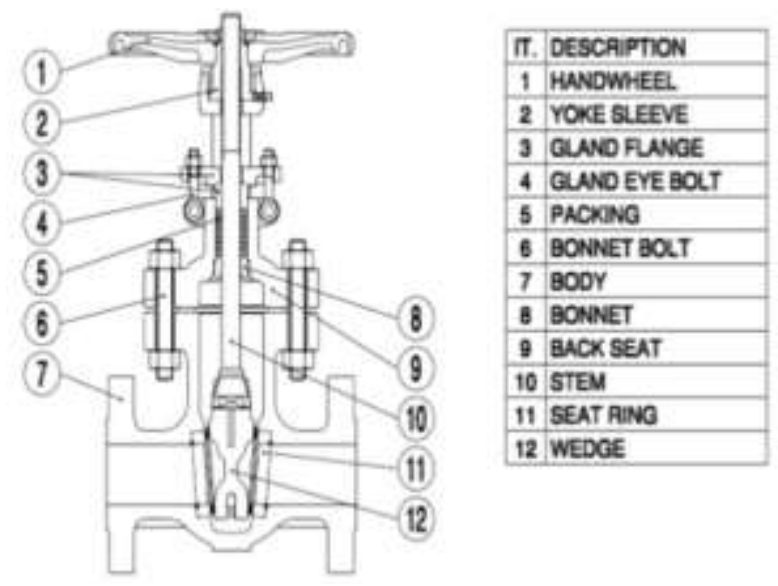

Gambar 7. Bagian-bagian utama gate valve. copyright is published under Lisensi Creative Commons Atribusi 4.0 Internasional. 


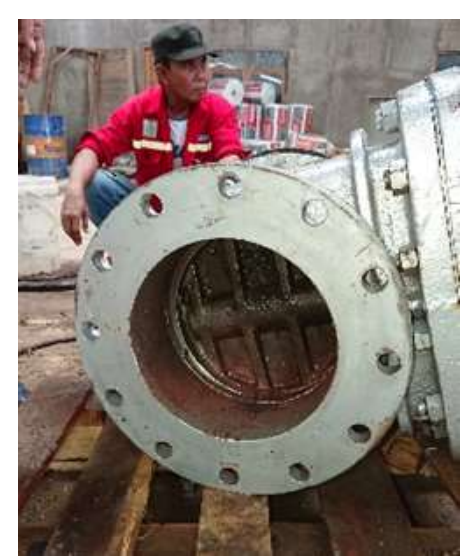

Gambar 8. Pemeriksaan hasil uji.

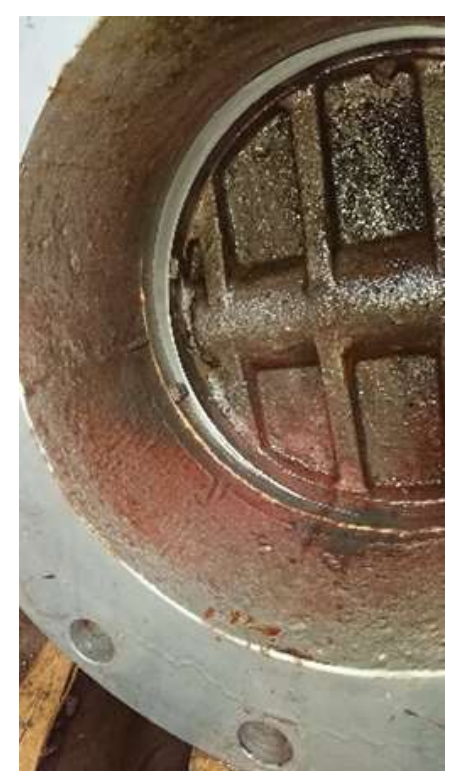

Gambar 9. Bagian Disc yang mengalami kebocoran.

Seat adalah bagian pada valve yang diam sedangkan disc adalah bagian yang bergerak, bertugas sebagai pengontrol aliran. Disc akan bergerak ke atas sehingga memberikan ruang lebih banyak agar fluida dapat mengalir, bergerak ke bawah jika akan menutup dan menekan seat dengan rapat.

\section{KESIMPULAN}

Proses pengujian valve di galangan kapal PT. Krakatau Shipyard berlangsung dengan baik. Dari hasil pengujian 4 buah gate vale ditemukan kebocoran pada salah satu valve yaitu pada bagian disc. Rekomendasi yang diberikan oleh pihak BKI untuk kebocoran tersebut adalah diperbaiki dengan cara menutupi kebocoran menggunakan bahan yang disarankan dari pabrikan pembuatan gate valve tersebut yaitu menggunakan lem besi. Proses pengujian gate valve terlaksana dengan baik dan benar dengan mengikuti prosedur serta urutan yang telah disampaikan pada pembahasan sebelumnya.

\section{UCAPAN TERIMA KASIH}

Penulis mengucapkan terima kasih kepada PT. BKI (Persero) Cabang Madya Klas Banten dan PT. Krakatau Shipyard di Bojonegara yang menjadi tempat penelitian ini. 


\section{DAFTAR PUSTAKA}

[1] Grammenos, C. T. 2010. "The Handbook of Maritime Economics 2nd. Ed". Cornwall: Exeter Premedia Services, MPG Books.

[2] Malvino, K. “www.emaritim.com", 11 Agustus 2017. [Online]. Available: https://www.emaritim.com/2017/08/ledakan-km-kendhaga-nusantara-berasal.html. [Accessed 05 Juny 2020].

[3] Peter Smith, R. W. Zappe, Valve Selection Handbook: Engineering Fundamentals for Selecting the Right Valve Design for Every Industrial Flow Application, Fifth Edition, Elsevier, USA, 2004.

[4] Marine Machinery, Engines \& Controls. "www.brighthubengineering.com", 30 Juni 2009. [Online]. Available: https://www.brighthubengineering.com/marine-engines-machinery/41043-procedure-of-swpump-sea-chest-cleaning/. [Accessed 05 July 2020].

[5] Biro Klasifikasi Indonesia. 2016. "Rules for Machinery Volume III". Jakarta: Biro Klasifikasi Indonesia. 